\title{
Epigenetic Mechanisms for the Early Environmental Regulation of Hippocampal Glucocorticoid Receptor Gene Expression in Rodents and Humans
}

\author{
Tie Yuan Zhang ${ }^{1}$, Benoit Labonté ${ }^{1}$, Xiang Lan Wen ${ }^{1}$, Gustavo Turecki ${ }^{1}$ and Michael J Meaney ${ }^{*, 1,2,}$ \\ ${ }^{1}$ Sackler Program for Epigenetics Psychobiology and Departments of Psychiatry and Neurology \& Neurosurgery, \\ McGill University, Montreal, Quebec, Canada; ${ }^{2}$ Singapore Institute for Clinical Sciences, Singapore, Singapore
}

Parental care influences development across mammals. In humans such influences include effects on phenotypes, such as stress reactivity, which determine individual differences in the vulnerability for affective disorders. Thus, the adult offspring of rat mothers that show an increased frequency of pup licking/grooming (ie, high LG mothers) show increased hippocampal glucocorticoid receptor (GR) expression and more modest hypothalamic-pituitary-adrenal responses to stress compared with the offspring of low LG mothers. In humans, childhood maltreatment associates decreased hippocampal GR expression and increased stress responses in adulthood. We review the evidence suggesting that such effects are mediated by epigenetic mechanisms, including DNA methylation and hydroxymethylation across GR promoter regions. We also present new findings revealing associated histone post-translational modifications of a critical GR promoter in rat hippocampus. Taken together these existing evidences are consistent with the idea that parental influences establish stable phenotypic variation in the offspring through effects on intracellular signaling pathways that regulate the epigenetic state and function of specific regions of the genome.

Neuropsychopharmacology Reviews (2013) 38, II I-123. doi: I0. I038/npp.20 I2.149; published online 12 September 2012

Keywords: parental care; DAN methylation; hippocampus; glucocorticoid receptor; histone post-translational modifications

\section{INTRODUCTION}

The quality of family life influences the development of individual differences in vulnerability for multiple forms of mental illness, including affective illnesses. As adults, victims of childhood physical or sexual abuse or parental neglect are at considerably greater risk for affective disorders (eg, Bifulco et al, 1991; Brown and Anderson, 1991; McCauley et al, 1997; Felitti et al, 1998; Shonkoff et al, 2009). These findings were confirmed in a prospective, longitudinal study that confirms the link between abuse/neglect and depression (Widom et al, 2007). Moreover, childhood maltreatment also associates with an increased severity of illness, reduced treatment responsivity, and increased comorbidity (Widom et al, 2007). Broader forms of familial dysfunction including persistent emotional and physical neglect, family conflict, and conditions of harsh, inconsistent discipline compromise cognitive and emotional development (Ammerman et al, 1986; Trickett and McBrideChang, 1995; Repetti et al, 2002; Lupien et al, 2009) and

${ }^{*}$ Correspondence: Dr MJ Meaney, Douglas Institute, 6875 boul LaSalle, Montréal, Québec, Canada H4H 1R3, Tel: +1 5147616131 x3938, Fax: +1 514888 4081, E-mail: michael.meaney@mcgill.ca Received 3 April 2012; revised 31 May 2012; accepted 31 May 2012 increase the risk for depression and anxiety disorders (Holmes and Robins, 1987, 1988; Gottman, 1998; Hill et al, 2001) to a level comparable to that for abuse. More subtle relationships exist. Low scores on measures of parental bonding, reflecting cold, distant parent-child relationships, particularly low maternal care, are associated with a significantly increased risk of depression and anxiety in later life (eg, Canetti et al, 1997; Parker, 1981; Kendler et al, 2002; Hill et al, 2000). And again, the risk is not unique to mental health. Russak and Schwartz (1997) found that by midlife, those individuals who, as undergraduate students, rated their relationships with parents as cold and detached had a fourfold greater risk of chronic illness, including depression and alcoholism, as well as heart disease and diabetes. Family life also serves as a source of resilience in the face of chronic stress (Rutter, 1979). Thus, warm, nurturing families tend to promote resistance to stress and to diminish vulnerability to stress-induced illness (Smith and Prior, 1995; Repetti et al, 2002). The epidemiology of affective disorders reflects the profound influence of family life on neural development and mental health.

Parental factors also serve to mediate the effects of adversity derived from extra-familial sources on neurodevelopment 
(Hackman et al, 2010). For example, the effects of poverty on emotional and cognitive development are mediated by parental factors to the extent that if such factors are controlled, there is no discernible effect of poverty on child development (Conger and Donnellan, 2007; McLloyd, 1998; also see Linver et al (2002)). Treatment outcomes associated with early intervention programs are routinely correlated with changes in parental behavior: In cases where parental behavior proves resistant to change, treatment outcomes for the children are seriously limited. The effects of intervention programs that directly target parent-child interactions on endophenotypes associated with affective disorders (eg, Belsky, 1997; Olds et al, 1998; Klein Velderman et al, 2006; Van Zeijl et al, 2006) provide evidence for the causal influence of parenting on mental health.

\section{THE BIOLOGY OF PARENTAL INFLUENCES}

A critical question concerns the mechanisms that mediate the enduring parental influence on the health of offspring. The relationship between social influences over development and health in adulthood appears to be, in part, mediated by the development of individual differences in neural systems that underlie the expression of behavioral and endocrine responses to stress (Seckl and Meaney, 1994; Nemeroff, 1996; Sroufe, 1997; Francis et al, 1999; Francis et al, 1999a; Repetti et al, 2002; Fish et al, 2004; Klaassens et al, 2009; Cichetti et al, 2010). Thus, physical and sexual abuse in early life increases endocrine and autonomic responses to stress in adulthood (DeBellis et al, 1994; Heim et al, 2000). Likewise, variations in parental care associate with individual differences in neuroendocrine and autonomic responses to stress in humans (Flinn and England, 1995; Leucken, 1998, 2000; Pruessner et al, 2004; Taylor et al, 2004; Taylor et al, 2006), as well as emotional reactivity (Reid and Crisafulli, 1990; and see Repetti et al (2002)). Finally, there is considerable evidence in favor of the hypothesis that individual differences in stress reactivity associate with the risk for depression (Wichers et al, 2007, 2009). Thus, the influence of familial depressive illness is, in part at least, mediated by increased stress reactivity, enhancing the response of the individual to mild, regular stressors (ie, hassles).

Parental effects occur across a variety of species from plants to mammals (Meaney, 2001; Cameron et al, 2005; Maestripieri and Mateo, 2009). Such effects imply an enduring influence of environmental signals operating during early development on genome function. We explore the potential mechanisms for such parental effects examining the influence of variations in maternal care in the rat on the development of individual differences in behavioral and endocrine responses to stress. Lactating female Long-Evans rats (an out-bred strain of rattus norvegicus) exhibit considerable variation in the frequency of pup licking/ grooming (LG; Champagne et al, 2003). Individual differences in the frequency of pup LG among adult female rats are reliable across multiple litters, and thus a stable feature of the maternal phenotype. We use observational procedures to define mothers that consistently show high or low levels of pup LG (ie, high vs low LG mothers). Variations in pup LG over the first week of postnatal life rat affect the development of behavioral and hypothalamicpituitary-adrenal (HPA) responses to stress in adulthood (Liu et al, 1997; Caldji et al, 1998; Francis et al, 1999; Menard et al, 2004; Weaver et al, 2004, 2005; Zhang et al, 2006; Toki et al, 2007). Behavioral responses to environmental stressors include a cessation of exploration or appetitive behavior (Caldji et al, 1998; Francis et al, 1999; Weaver et al, 2006; Toki et al, 2007), as well as active attempts to escape from threat (Menard et al, 2004). For example, in a novely-induced suppression of feeding test in which food-deprived animals are provided food in a novel context, the adult offspring from high LG mothers show a shorter latency to begin eating and eat for a longer period of time (Caldji et al, 1998; O'Donnell, unpublished observation). The offspring of low LG mothers also show increased vulnerability for stress-induced learned helplessness (Kurata et al, 2009).

Likewise there are differences in HPA responses to acute stress apparent in both circulating levels of pituitary adrenocorticotropin (ACTH) and adrenal corticosterone. As adults, the offspring of high LG mothers show more modest plasma ACTH and corticosterone responses to acute stress in comparison with animals reared by low LG mothers (Liu et al, 1997; Weaver et al, 2004, 2005; Champagne et al, 2003; Toki et al, 2007; Kurata et al, 2009). Circulating glucocorticoids act at glucocorticoid receptor (GR) sites in corticolimbic structures, such as the hippocampus, to regulate HPA activity. Such feedback effects target corticotropin releasing factor (CRF) synthesis and release at the level of the paraventricular nucleus of the hypothalamus (PVNh). The offspring of high LG mothers show significantly increased hippocampal GR mRNA and protein expression, enhanced glucocorticoid negative feedback sensitivity, and decreased hypothalamic CRF mRNA levels. Importantly, hippocampal infusion of a GR antagonist completely eliminates the maternal effect on HPA responses to stress, suggesting a direct relation between hippocampal GR expression and the magnitude of the HPA response to stress.

Importantly, effects of maternal care on gene expression and stress responses of the adult offspring are reversed with cross-fostering (Francis et al, 1999; Caldji et al, 2003; Weaver et al, 2004): stress responses of adult animals born from low LG mothers and reared by high LG dams are comparable to normal offspring of high LG mothers (and vice versa). Moreover, variations in the frequency of pup LG toward individual pups of the same mother are significantly correlated with hippocampal GR expression in adulthood (van Hasselt et al, 2012). These findings, as well as those from studies that directly manipulate the frequency of pup LG by the dam reveal a direct relation between maternal care and the phenotypic development of the offspring. 


\section{MOLECULAR TRANSDUCTION OF PARENTAL SIGNALS}

Tactile stimulation derived from maternal licking appears to be the critical environmental signal for the regulation of hippocampal GR expression in the neonate. In vivo studies with rat pups or in vitro studies using cultured hippocampal neurons suggest that maternal effects on hippocampal GR expression are mediated by increases in hippocampal serotonin (5-HT) turnover and the expression of the nerve-growth factor-inducible factor-A (NGFI-A) transcription factor (Meaney et al, 2000; LaPlante et al, 2002; Mitchell et al, 1990, 1992). In vitro, 5-HT through the activation of a $5-\mathrm{HT}_{7}$ receptor increases the activity of cAMP-dependent signaling pathways in hippocampal neurons, resulting in elevated expression of NGFI-A. The effect of various 5-HT agonists on GR expression in hippocampal neurons is strongly correlated with the effect on cAMP formation. Activation of these signaling cascades leads to an increased GR expression. In cultured hippocampal neurons, the effect of $5-\mathrm{HT}$ on GR expression is (1) blocked by $5-\mathrm{HT}_{7}$ receptor antagonists or inhibitors of protein kinase A, (2) mimicked by $5-\mathrm{HT}_{7}$ receptor agonists or treatments with stable cAMP analogs, and (3) eliminated by antisense or siRNA knockdown of NGFI-A mRNA (Weaver et al, 2007; Hellstrom et al, in press). In vivo, the effect on GR is blocked with 5HT receptor antagonists (Mitchell et al, 1990, 1992). Moreover, the increase in hippocampal 5-HT activity is associated with a maternally regulated increase in the conversion of thyroxine to triidodithyronine (T3; Hellstrom et al, in press): T3 administration in neonatal period, which regulates the 5-HT systems activity, mimics the effects of increased pup LG on both NGFI-A expression and hippocampal GR programming (Meaney et al, 1987; Mitchell et al, 1990; Hellstrom et al, in press). Interestingly, the activation of ascending 5-HT systems during postnatal development also regulates the development of corticolimbic systems implicated in fear behavior (Gross et al, 2002; Gross and Hen, 2004).

The 5' non-coding variable exon 1 region of the hippocampal GR gene (Figure 1) contains multiple alternate promoter sequences including a neuron-specific, exon $1_{7}$ sequence (McCormick et al, 2000). Increased pup LG enhances hippocampal expression of GR mRNA splice variants containing exon $1_{7}$ sequence (McCormick et al, 2000; Weaver et al, 2004, 2007; Hellstrom et al, in press), which contains an NGFI-A response element (Crosby et al, 1991). Pup LG increases hippocampal NGFI-A expression and binding to the exon $1_{7}$ promoter (Weaver et al, 2004, 2007; Hellstrom et al, in press). Cotransfection of an NGFIA vector and an exon $1_{7}$-luciferase construct shows increased luciferase activity, reflecting NGFI-A-induced activation of transcription through the exon $1_{7}$ promoter (Weaver et al, 2007; Hellstrom et al, in press). The effect of NGFI-A is eliminated by a site-directed mutation within the NGFI-A response element of the exon $1_{7}$ promoter (Weaver et al, 2007) revealing that it is the physical interaction of NGFI-A with its response element that triggers the increase in transcriptional activity. Moreover, infection of hippocampal neurons with an NGFI-A expression plasmid increases both total GR mRNA and exon $1_{7}$-containing GR mRNA (Hellstrom et al, in press). A series of in vivo studies show that the association of NGFI-A with the exon $1_{7}$ promoter is actively regulated by pup LG and artificially generated tactile stimulation of the pups yields the same effect (Hellstrom et al, in press). Thus, chromatin immunoprecitipation (ChIP) assays reveal increased binding of NGFI-A to the exon $1_{7}$ promoter in pups of high compared with low LG mothers, but only in the period following a nursing bout with pup LG: hippocampal tissue samples obtained 20 min following a nursing bout, with no subsequent interaction between the mother and pup, do not

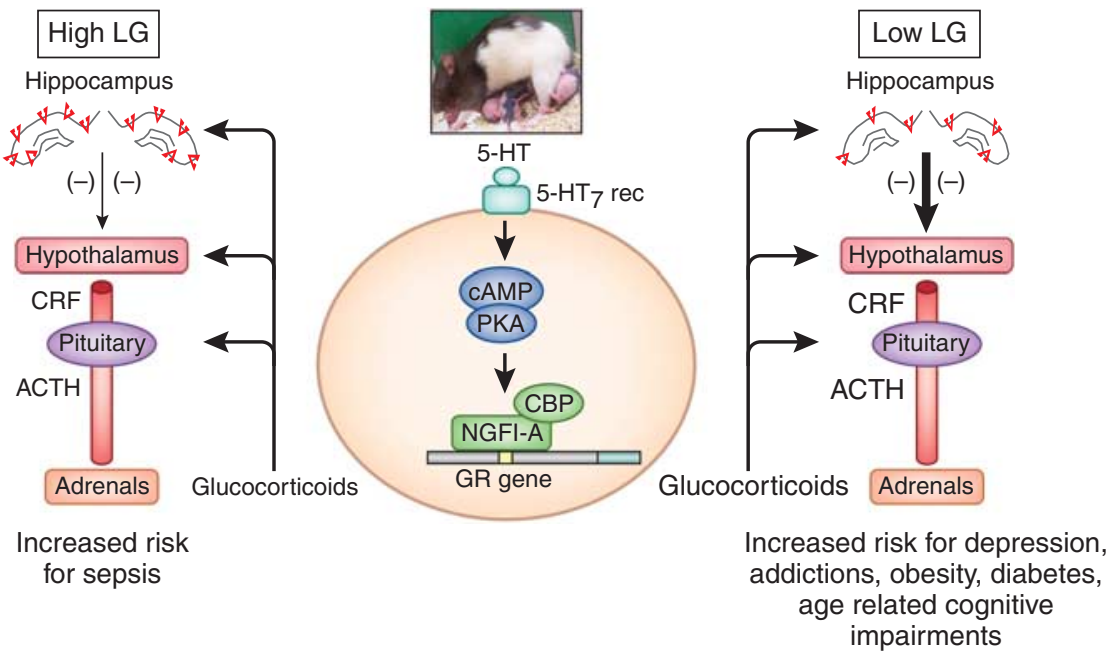

Figure 1. Glucocorticoid receptor gene organization. Schema describing the organization of the rat and human glucocorticoid receptor gene, including the 9 exon regions. Exons 2-9 code for the glucocorticoid receptor protein. Exon 1 is comprised of multiple, tissue-specific promoter regions (rat is based on McCormick et al (2000) and human on Turner and Muller (2005)). The rat exon $1_{7}$ sequence shares $~ 70 \%$ sequence homology with the human exon $1_{\mathrm{F}}$ sequence, and both are highly expressed in hippocampus. ACTH, adrenocorticotropin; CRF, corticotropin releasing factor. 
reveal the difference in NGFI-A association. Perhaps most convincingly, artificial tactile stimulation of pups increases hippocampal NGFI-A expression and NGFI-A binding to the exon $1_{7}$ promoter.

There is a similar effect on hippocampal GAD1 (Zhang et al, 2010), an NGFI-A-regulated gene that encodes for glutamic acid decarboxylase, the rate-limiting enzyme for GABA synthesis. The association of NGFI-A with the GAD1 promoter is increased in the offspring of high compared with low LG mothers, but only following a nursing bout. Similarly, hippocampal neuronal cultures treated with 5-HT show an increase in GAD1 expression and the effect is blocked by an siRNA targeting NGFI-A. These findings suggest that maternal care regulates the expression of a range of NGFI-A-sensitive genes.

However, the critical issue concerns the mechanism by which hippocampal GR expression remains elevated following weaning and separation from the mother. One possibility is that the increased NGFI-A-exon $1_{7}$ interaction occurring within hippocampal neurons in the pups of high LG mothers might result in an epigenetic modification of the exon $1_{7}$ sequence that alters NGFI-A binding and maintains the maternal effect into adulthood. We focused our initial studies on potential influences on DNA methylation with the assumption that this relatively stable covalent modification was a reasonable candidate mechanism for the enduring effects of maternal care on hippocampal gene expression in the rat.

\section{THE EPIGENETICS OF PARENTAL EFFECTS}

Preliminary studies revealed greater methylation across the entire exon $1_{7} \mathrm{GR}$ promoter sequence in the hippocampus of adult offspring of low LG mothers. These findings suggest a parental effect on DNA methylation patterns in the offspring. More focused approaches examined the methylation status of individual $\mathrm{CpGs}$ in the exon $1_{7}$ sequence using sodium bisulfite mapping. The results reveal significant differences in methylation at the $5^{\prime} \mathrm{CpG}$ dinucleotide of the NGFI-A consensus sequence. This site is hypermethylated in the offspring low LG mothers, and hypomethylated in those of high LG dams. Cross-fostering reverses the differences in the methylation of the $5^{\prime} \mathrm{CpG}$ site and suggests a direct relation between maternal care and DNA methylation of the exon $1_{7}$ GR promoter (Weaver et al, 2004). The effect of maternal care is remarkably specific, with highly significant alterations in the methylation status of the $5^{\prime} \mathrm{CpG}$, and no effect at the 3' site. Nevertheless, although less striking, there are differences in the frequency of methylation at other $\mathrm{CPG}$ sites on the exon $1_{7}$ promoter.

An alternative form of DNA methylation, 5-hydroxymethylcytosine, has recently been identified, although its function is not been fully understood. Bisulfite sequencing or PCR-based approaches to the study of DNA methylation cannot distinguish between 5-methylcytosine and 5-hydroxymethylcytosine. Interestingly, the ten-eleven translocation family of enzymes can convert 5-methylcytosine to 5hydroxymethylcytosine. 5-Hydroxymethylcytosine has been found widely distributed in embryonic stem (ES) cells, suggesting a possible function in gene regulation in ES cells. 5-Hydroxymethylcytosine has also been found enriched in certain neuronal cells (Kriaucionis and Heintz, 2009). Maternal care has a sustained effect on GRexon $1_{7}$ DNA methylation, which cannnot exclude possible involvement of 5-hydroxymethylcytosine. We analyzed 5-hydroxymethylcytosine level in the hippocampal GRexon $1_{7}$ promoter in rats using antibody capture (ie, 5-hydroxymethylcytosine-dependent immunoprecitipation) of hippocampal DNA. We found the level of 5-hydroxymethylcytosine of the exon $1_{7}$ GR promoter was three times higher in hippocampal samples from the offspring of low compared with high-LG mothers (Figure 2), suggesting that the differences in DNA methylation at this site reflect, in part at least, differences in
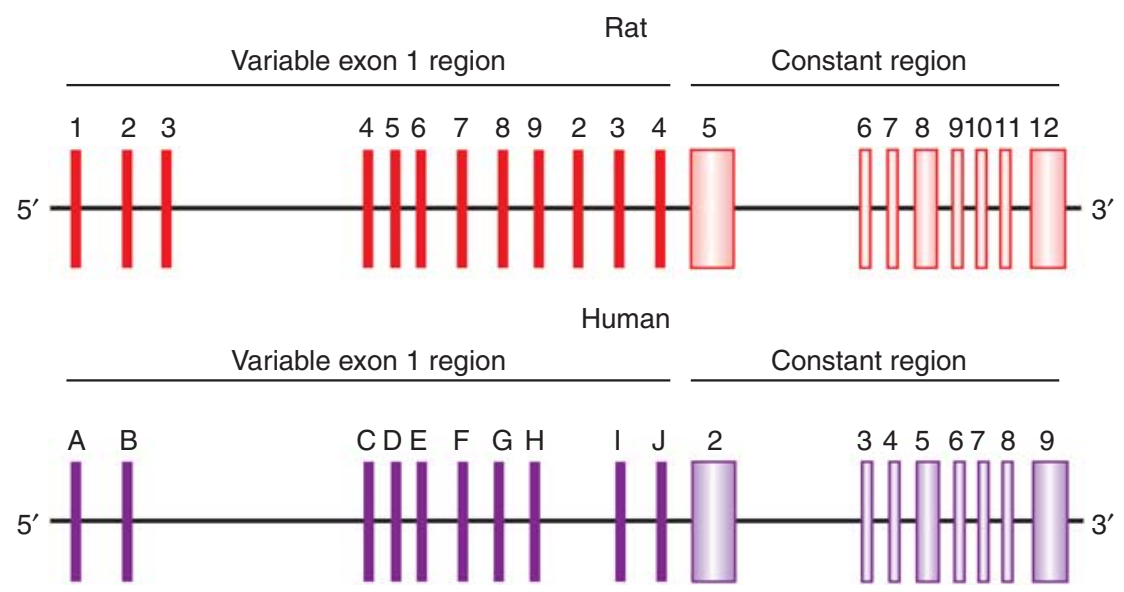

Figure 2. DNA 5-hydroxymethylcytosine (5-hmC) analysis of the exon $1_{7}$ GR promoter. Mean \pm SEM percentage levels of 5-hmC expressed as a percentage of input DNA from a 5-hmC-dependent immunoprecipitation of GR exon $1_{7}$ promoter in hippocampal sample from adult offspring of high and low licking/grooming (LG) mothers ( $n=3-4 /$ group). Unmethylated and methylated controls showed negligible signal (ie, 0-3\%) using a commercially available 5hmC-immunoprecipiation assay (DiagenodeCat. No. AF-104-0016). GR, glucocorticoid receptor; NGF-I, nerve-growth factor-inducible factor-A. 
5-hydroxymethylcytosine. The overall level of DNA methylation is dynamic during the period of early postnatal development, a time when the differences in the frequency of pup LG between high and low LG mothers are apparent. Whether 5-hydroxymethylcytosine is also dynamic over this period and directly influenced by maternal care remains to be determined.

As DNA methylation favors a closed chromatin structure, the difference in methylation within the 5' $\mathrm{CpG}$ dinucleotide of the NGFI-A response element suggests alteration of NGFI-A binding to the exon $1_{7}$ sequence. In vitro binding of purified recombinant NGFI-A protein to its response element using electrophoresis mobility shift assays indicate that methylation of the $5^{\prime} \mathrm{CpG}$ dinucleotide in the NGFI-A response element of the exon $1_{7}$ GR promoter inhibits NGFI-A protein binding (Weaver et al, 2004). Transfection studies show that (1) NGFI-A induces transcription through the exon $1_{7}$ promoter and (2) DNA methylation of a transfected exon $1_{7}$ construct inhibits the ability of NGFI-A to bind and activate its expression (Weaver et al, 2007; Hellstrom et al, in press). Likewise, ChIP assays indicate increased acetylated lysine 9 (K9)- histone $\mathrm{H} 3$ and a threefold greater binding of NGFI-A to the exon $1_{7}$ GR promoter in hippocampal samples obtained from the adult offspring of high compared with low LG mothers (Weaver et al, 2004, 2005). Importantly, such differences occur despite a comparable level of hippocampal NGFI-A expression in the adult offspring of high and low LG mothers. Thus, the methylation of the $5^{\prime} \mathrm{CpG}$ site alters the 'affinity' of the NGFI-A consensus sequence for its ligand, resulting in a decreased level of NGFI-A binding. Finally, the sequencing involved in these studies has yet to reveal any evidence for sequence variation in this region. Thus, to our knowledge, the individual differences in GR expression in this model associates with variation at the level of epigenetic state, and not in nucleotide sequence.

The ability of DNA methylation to regulate the capacity for histone modifications, especially histone acetylation, forms a prominent link between methylation and transcription. The electrostatic bonds formed between the positively charged histone proteins and their negatively charged DNA partners demands an active chromatin remodeling process for transcriptional activation (Turner, 2001; Taverna et al, 2007). Chromatin remodeling is achieved through biochemical modifications of the histone proteins that control chromatin structure and thus genome function. The posttranslational modifications to the histones occur through a series of enzymes that bind to the histone tails and modify the local chemical properties of specific amino acids (Shahbazian and Grunstein, 2007; Grunstein, 1997; Hake and Allis, 2006; Jenuwein and Allis, 2001; Taverna et al, 2007). For example, histone acetylation neutralizes the positive charge on the histone tail, opening chromatin and increasing the access of transcription factors to their DNAbinding sites. Acetylation commonly occurs at lysine residues, such as the $\mathrm{H} 3 \mathrm{~K} 9$, and is catalyzed by histone acetyltransferases and reversed by HDACs. HDACs remove
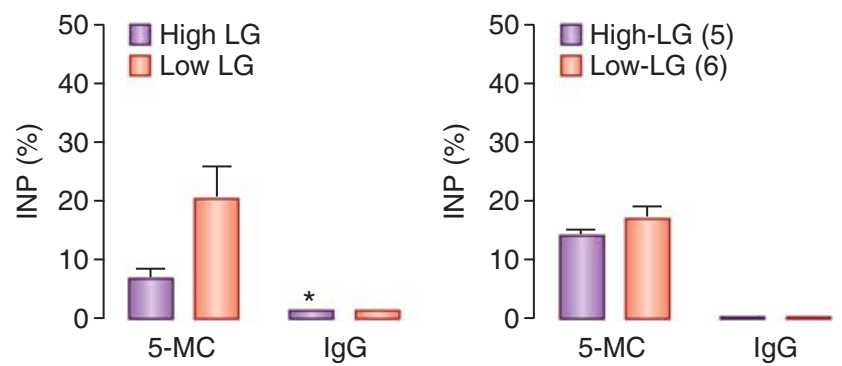

Figure 3. Histone post-translational modifications associated with the exon 17 GR promoter in rat hippocampus. Mean \pm SEM levels of various histone modifications associated with the exon 17 GR promoter determined using serial micro chromatin-immunoprecipitation assays in the same hippocampal samples from adult offspring of high and low licking/grooming (LG) mothers (all antibodies form Santa Cruz). The data are expressed as a ratio of the input DNA. The middle panel reveals the correlation between levels of H3K9ac and H3K4me3.

acetyl groups from histone tails and prevent subsequent acetylation (Shahbazian and Grunstein, 2007; Szyf, 2009). Cytosine methylation attracts repressor complexes comprised of HDACs such that DNA methylation and histone acetylation are usually inversely related. $\mathrm{H} 3 \mathrm{~K} 9 \mathrm{ac}$ associates with increased transcription and we found increased $\mathrm{H} 3 \mathrm{~K} 9 \mathrm{ac}$ of the exon $1_{7}$ GR promoter (Weaver et al, 2004, 2007; Figure 3) genes in hippocampus from the adult offspring of high compared with low LG mothers. This pattern is similar to maternal effects on hippocampal GAD1 or Grm1 expression; in each case decreased DNA methylation within promoter regions associates with increases in both $\mathrm{H} 3 \mathrm{~K} 9 \mathrm{ac}$ and gene transcription (Zhang and Meaney, 2010; Bagot et al, submitted). H3K9ac tends to associate with stably transcribed regions of the genome, which is consistent with the idea of a persistent increase in hippocampal GR transcription in the adult offspring of high LG mothers.

Histone acetylation directly modifies chromatin structure through effects on the local physicochemical environment that define the chromatin state (Turner, 2001; Taverna et al, 2007). Additional histone modifications, notably histone methylation, influence transcription through indirect pathways that involve a complex array of transcriptional mediators (Shahbazian and Grunstein, 2007; Grunstein, 1997; Hake and Allis, 2006; Jenuwein and Allis, 2001; Bernstein et al, 2005; Berger, 2007; Kouzarides, 2007; Taverna et al, 2007). Multiple lysine and arginine residues on the histone tails are subject to methylation, which is catalyzed by distinct histone methyltransferases and reversed by histone demethylases. This process provides a signaling pathway that begins with the activation of the intracellular signals that activate the individual methylating or demethylating enzymes producing a specific epigenetic profile on the histone tails. This process links specific intracellular signals to specific histone methylation marks. The methylation profile of the histone tails is highly variable. Methylation can occur at multiple sites along the histone tails and vary in the level of methylation (mono-, di-, or tri-methylation). The resulting profile acts as a 'code' (Hake and Allis, 2006; 
Jenuwein and Allis, 2001; Taverna et al, 2007; Zhang et al, 2010a) for various protein complexes that remodel chromatin and alter transcriptional activity; thus, indicating an indirect influence of histone methylation on transcription.

Certain histone modifications covary. An example of relevance here is that of $\mathrm{H} 3 \mathrm{~K} 9 \mathrm{ac}$ and $\mathrm{H} 3 \mathrm{~K} 4 \mathrm{me}$. Both marks are generally present at actively transcribed regions of the genome (Ruthenburg et al, 2007a; Pokholok et al, 2005; Millar and Grunstein, 2006). Thus, we find increased $\mathrm{H} 3 \mathrm{~K} 9 \mathrm{ac}$ and $\mathrm{H} 3 \mathrm{~K} 4 \mathrm{me} 3$ at both regions of the exon $1_{7} \mathrm{GR}$ promoter and the levels of these individual marks are very highly correlated (Figure 4).

H3K4me, whether in the mono-, di-, or tri-methylated state, appears to protect $\mathrm{CpG}$ islands against methylation (Ooi et al, 2007; Thompson et al, 2010). Thus, genome-wide analyses reveal a negative correlation between $\mathrm{H} 3 \mathrm{~K} 4 \mathrm{me}$ and $\mathrm{CpG}$ methylation. Interestingly, $\mathrm{H} 3 \mathrm{~K} 4 \mathrm{me} 3$ appears to actively 'repel' the binding of the DNA methyltransferase, DNMT3L, which is essential for de novo methylation and attracts complexes containing histone acetyltransferases that open chromatin and enhance transcription factor binding (Ooi et al, 2007). Indeed, the absence of $\mathrm{H} 3 \mathrm{~K} 4 \mathrm{me} 3$ seems to be a prerequisite for the recruitment of de novo $\mathrm{D}$ (DNMTs) and the acquisition of DNA methylation (Ooi et al, 2007; Thompson et al, 2010; Ciccone et al, 2009). The same relation was apparent across the exon $1_{7}$ GR promoter, where the decreased level of DNA methylation was associated with an increased level of $\mathrm{H} 3 \mathrm{~K} 4 \mathrm{~m} 3$ (Figures 3 and 4). H3K4me3 targets the chromatin remodeling factor (NURF) and the Yng1 protein in the $\mathrm{NuA} 3$ (nucleosomal acetyltransferase of histone H3) complex to genes increasing the level of histone acetylation and transcriptional activation. This process explains the tight correlation between the levels of $\mathrm{H} 3 \mathrm{~K} 4 \mathrm{me} 3$ and $\mathrm{H} 3 \mathrm{~K} 9 \mathrm{ac}$.

These findings suggest that variations in maternal care influence the methylation state of the exon $1_{7}$ GR promoter in hippocampus, regulating NGFI-A binding, GR transcription, and HPA stress responses. The effect of $\mathrm{CpG}$ methylation on gene expression is, in part, mediated by the recruitment of HDAC-containing repressor complexes (Turner, 2001; Bird and Wolffe, 1999; Bird, 2001; Klose and Bird, 2006; Li, 2002; Miranda and Jones, 2007; Nan et al, 1998), HDAC inhibitors permit chromatin remodeling and transcription factor binding, and may thus liberate the expression of genes from methylation-induced repression. HDAC inhibition also reverses the maternal effects on hippocampal GR expression (Weaver et al, 2004). Chronic, central infusion of adult offspring of low LG mothers with the broad-spectrum HDAC inhibitor, trichostatin A (TSA; Weaver et al, 2006), significantly increased H3K9 acetylation, NGFI-A binding to the GR-1 7 promoter, and GR expression to levels comparable to those observed in the offspring of high LG mothers. TSA infusion also eliminated the effect of maternal care on HPA responses to acute stress. These results suggest a direct relation between maternal care, histone acetylation, DNA methylation of the GR-1 promoter, GR expression, and HPA responses to stress.


Figure 4. Histone post-translational modifications associated with the exon 17 GR promoter in rat hippocampus. Mean \pm SEM levels of various histone modifications associated with the exon 17 GR promoter determined using serial micro chromatin-immunoprecipitation assays in the same hippocampal samples from adult offspring of High and Low LG mothers (all antibodies form Santa Cruz). The data are expressed as a ratio of the input DNA. The middle panel reveals the correlation between levels of H3K9ac and H3K4me3.

An obvious concern is whether the effects of maternal care on hippocampal GR expression represent a more global process in which variations in parental signals affect the methylation status of broad regions of the genome. Other studies reveal that stress-induced variations in maternal care in rat, including the frequency of pup LG, alter the methylation state of the $b d n f$ gene in hippocampus (Roth et al, 2009). In the mouse, prolonged periods of maternal separation alter the methylation state of the promoter for the arginine vasopressin gene (AVP), increasing hypothalamic AVP synthesis and HPA responses to stress (Murgatroyd et al, 2009). Maternal separation in the rat associates with reduced $\mathrm{GABA}_{\mathrm{A}}$ receptor levels in the locus coeruleus (LC) and the nucleus tractus solitarius (NTS) as well as levels of the mRNA for the $\gamma_{2}$ subunit of the GABA receptor complex, which confers high-affinity benzodiazepine binding in the amygdala as well as in the LC and NTS (Caldji et al, 2000). Both the amygdala and the ascending noradrenergic systems have been considered as critical sites for the anxiolytic effects of GABAergic inhibition. These 
findings suggest that parental influences might influence the epigenetic regulation of multiple regions of the genome in different brain regions to produce a coordinated effect on the stress response of the offspring.

The NGFI-A-regulated GAD1 gene shows a similar increase in the level of promoter methylation in the hippocampus from the adult offspring of low LG mothers (Zhang et al, 2010). Moreover, a ChIP-chip study using high-density oligonucleotide microarrays tiling a contiguous 7 million base pair region of rat chromosome 18 containing the NR3C1 gene at $100 \mathrm{bp}$ spacing reveal coordinated alterations in $\mathrm{H} 3-$ K9 acetylation, DNA methylation, and gene expression across a number of areas in response to variations in maternal care, including a subregion containing multiple protocadherin genes (McGowan et al, 2011). These results suggest a broad epigenomic response to variations in maternal care that associates with an extensive difference in gene expression.

\section{DEVELOPMENTAL REGULATION OF HIPPOCAMPAL GR EXPRESSION IN HUMANS}

A critical question is whether familial influences operating during early development in humans are linked to the stable epigenetic regulation of gene expression as in rodents. There are obvious constraints on tissue access for molecular studies of neural function in humans. These limitations are of considerable importance in the study of epigenetics mechanisms, which are potentially tissue- and even celltype-specific. We were able to establish a translational program focusing on human hippocampus by virtue of the resources of the Québec Suicide Brain Bank (www.douglas.qc.ca/suicide). Approximately a third of individuals who die by suicide have histories of childhood adversity, including childhood sexual and physical abuse, as well as parental neglect. We (McGowan et al, 2009; Labonté et al, in press) thus showed decreased hippocampal GR expression in samples from suicide completers with histories of childhood maltreatment compared with controls (sudden, involuntary fatalities). The program is strengthened by a validated forensic interview that establishes developmental history and mental health status (Dumais et al, 2005; Zouk et al, 2006). Regression analyses across the samples showed no significant correlations between psychopathology, notably depression and substance disorders, and hippocampal GR expression. Rather the decreased hippocampal GR expression associated with a history of childhood maltreatment. There were no differences in hippocampal GR expression in samples from suicides negative for a history of childhood maltreatment. Instead, the differences in hippocampal GR expression were unique to suicide completers with a history of childhood maltreatment.

Splice variant analysis, comparable to that performed in the rat, revealed decreased expression of non-coding exons $1_{B}, 1_{C}, 1_{F}$, and $1_{H}$ in suicides with a history of childhood maltreatment compared with both controls and suicides without a history of maltreatment. These expression differences correlated with differential DNA methylation patterns between groups in the corresponding exon 1 variant promoters. The exon $1_{\mathrm{F}}$ sequence is of particular interest as it is the homolog of the rat exon $1_{7}$, is highly expressed in the brain, and contains an NGFI-A response element (Turner and Muller, 2005; McGowan et al, 2009; Figure 1). Moreover, the exon $1_{\mathrm{F}}$ sequence shows increased DNA methylation and decreased NGFI-A binding in samples from suicide victims with a history of maltreatment. These findings bear considerable similarity to the maternal effect in the rat and are suggestive of earlyenvironment regulation of the neural epigenome in humans. Of interest, recent studies in independent human samples investigating the effects of early-environmental adversity on exon $1_{\mathrm{F}}$ methylation reported consistent results (Radtke et al, 2011; Tyrka et al, 2012).

Decreased expression levels of GR exon $1_{B}, 1_{C}$, and $1_{H}$ transcripts were also associated with alterations in methylation of the respective sequences, with particular sites significantly correlated with expression levels. As expected on the basis of the expression data, the exon $1_{B}$ and $1_{C}$ regions showed increased methylation at predictive sites uniquely in samples from suicide/maltreatment subjects. However, analysis of the exon $1_{\mathrm{H}}$ GR promoter yielded an interesting profile that contrasted starkly with that observed for the other exon 1 regions (Labonté et al, in press). There was significantly increased DNA methylation of the exon $1_{\mathrm{H}}$ promoter in hippocampal samples from both controls and suicide victims without a history of maltreatment by comparison with those positive for maltreatment. And the methylation of the exon $1_{\mathrm{H}}$ promoter was positively correlated with hippocampal GR expression.

Most differentially methylated sites were found within putative transcription factors binding sites. Multiple transcription factors are predicted to bind promoters of GR non-coding exons (Turner et al, 2010), although, to date, only NGFI-A has been shown to activate transcription in the promoter of $\mathrm{GR} 1_{\mathrm{F}}$ (Weaver et al, 2007; Hellstrom et al, in press). Nevertheless, most of the CpG sites whose methylation state were investigated in $\mathrm{GR} 1_{\mathrm{B}}, \mathrm{GR} 1_{\mathrm{C}}$, and $\mathrm{GR} 1_{\mathrm{H}}$ promoters are predicted to bind transcription factors such as $\mathrm{Sp} 1$ and $\mathrm{Sp} 3$. Sp1 and $\mathrm{Sp} 3$ regulate GR basal expression (Nobukuni et al, 1995). Interestingly, there is evidence that Sp1 binding can alter the underlying methylation state of the DNA (Brandeis et al, 1994; MacLeod et al, 1994). Other known factors predicted to bind within the investigated promoter regions include NF-1, YY1, and members of the AP-1 family composed of Jun, Fos, and ATF. Interestingly, when interacting with Sp1/Sp3, these transcription factors can activate or repress transcription by recruiting cofactors inducing the opening or the closing of chromatin (Adams et al, 1995; Brodin et al, 2000; Hurst and Jones, 1987; Inoue et al, 1990; Kardassis et al, 1999; Laniel et al, 2001; Rafty et al, 2002; Roy and Guerin, 1994; Tapias et al, 2008). Consequently, hypermethylation in $\mathrm{GR} 1_{B}$ and $1_{C}$ promoters represses the binding of these 
transcription factors reducing expression, but at the same time the hypomethylated state in $\mathrm{GR} 1_{\mathrm{H}}$ permit $\mathrm{Sp} 1 / \mathrm{Sp} 3$ binding and the recruitment of HDACs close the chromatin state. Such models are currently a matter of speculation, but serve to underscore the importance of studies of the molecular mechanisms that link methylation at specific genomic regions with alterations in transcriptional activity. These findings also point to the potential for bidirectional relation between transcription factor binding and transcriptional activity and that of DNA methylation (Berger, 2007; Meaney and Ferguson-Smith, 2010).

Another important consideration is that of interpreting data from studies of DNA methylation in the brain. DNA methylation is a digital signal; an allele is either methylated or unmethylated at a specific site in a given cell. The percentage of methylation measured in DNA methylation studies represents the fraction of cells in which the allele is methylated. An increase in methylation levels indicates an increase in the number of cells that bear a methylated allele. As expected for functional promoters, many of which lie within CpG islands, methylation levels are commonly low. GR promoters are generally hypomethylated in the majority of neurons in the hippocampus (Oberlander et al, 2008; McGowan et al, 2009; Alt et al, 2010; Turner et al, 2010), suggesting that these regions are poised for transcriptional activation in the majority of neurons. Our results suggest that site-specific methylation in selected GR promoters, such as exons $1_{\mathrm{B}}, 1_{\mathrm{C}}, 1_{\mathrm{F}}$, and $1_{\mathrm{H}}$, varies in a fraction of cells in the hippocampus as a function of childhood maltreatment. We suggest that this difference results in the downregulation of hippocampal GR expression.

Forebrain GR activation inhibits HPA activity through tonic negative-feedback inhibition (de Kloet et al, 2005). Thus, selective knockdown of GR expression in the corticolimbic system in rodents is associated with increased HPA activity under basal and stressful conditions (Barden, 2004; Boyle et al, 2005, Ridder et al, 2005). Conversely, GR overexpression is associated with a dampened HPA response to acute stress (Reichardt et al, 2000).

Familial dysfunction in childhood associates with increased CRF activity (Lee et al, 2005) and enhanced HPA and autonomic stress reactivity (DeBellis et al, 1994; Heim et al, 2000; Essex et al, 2002; Teicher et al, 2002; Luecken and Lemery, 2004; Pruessner et al, 2004). Importantly, interventions that target parental care of high-risk children alter HPA activity (Fisher et al, 2000). In humans, decreased GR expression, altered corticosteroid feedback sensitivity and increased HPA activity are linked to major depressive disorder (de Kloet et al, 2005; Neigh and Nemeroff, 2006). And there is evidence for decreased hippocampal GR expression in depression (Webster et al, 2002). Polymorphisms in the $\mathrm{NR} 3 \mathrm{Cl}$ gene that encodes the GR result in GR resistance and enhance the risk for major depressive disorder (van Rossum et al, 2006; van West et al, 2004). Although not all depressed patients show evidence for increased hypercortisolemia, psychotic and treatment-resistant forms of depression are commonly associated with increased HPA activity (Schatzberg et al, 1985; Holsboer, 2000). Interestingly, childhood maltreatment is associated with more severe, treatment-resistant forms of depression. Successful treatment of such populations with antidepressants may require a normalization of HPA activity (Holsboer, 2000). The GR antagonist, mifepristone (RU486), which blocks the effects of elevated cortisol, has been successfully used as an adjunct in the treatment of psychotic depression (DeBattista et al, 2006).

\section{REVERSIBILITY OF DNA METHYLATION}

The issue of reversibility is critical for translational studies of the epigenomic consequences of early adversity. To our knowledge, the issue has yet to be directly addressed in humans, even in samples of non-neural origin. Nevertheless there is considerable evidence that suggests a capacity for the remodeling of epigenetic marks over the lifespan, including DNA methylation. Across multiple tissues, including brain, the methylation levels at specific regions change with age (Hernandez et al, 2011), reflecting the potential for dynamic variation.

The results of the TSA study described above suggest that DNA methylation patterns are dynamic and potentially reversible even in adult animals. Infusion of the HDAC inhibitor resulted in a significant, partial reversal of the maternal effect on DNA methylation (Weaver et al, 2004). These findings are consistent with previous in vitro studies showing that increased histone acetylation associated with HDAC inhibitors can trigger demethylation (Szyf, 2009). Conversely, intra-hippocampal infusion of the methyl donor amino-acid methionine (Weaver et al, 2005) leads to a hypermethylation of the exon $1_{7}$ GR promoter in the adult offspring of high LG animals. Thus, chronic central infusion of adult offspring of high or low LG mothers with methionine increases DNA methylation at the NGFI-A-binding site and reduces NGFI-A binding to the exon $1_{7}$ promoter sequence selectively in the offspring of high LG mothers. These effects eliminate group differences in both hippocampal GR expression and HPA responses to stress. Methionine increases the levels of SAM and DNA methylation (Tremolizzo et al, 2005). SAM could increase DNA methylation through either the activation of DNA methylation enzymes (Pascale et al, 1991) or by inhibiting demethylase activity (Szyf et al, 2004). Likewise, studies of transcriptional regulation of reelin and GAD1 reveal evidence for dynamic regulation of methylation states in mature cortical neurons through the disruption of repressor complexes and the inhibition of DNMT expression (Grayson et al, 2005; Kundakoic et al, 2007; Noh et al, 2005). Although the precise mechanisms for each of these effects is as yet unclear, these studies imply that mature brain cells express the enzymes necessary for both methylation and demethylation.

These findings are consistent with an emerging characterization of the potential for dynamic modifications in DNA methylation. Perhaps the most compelling evidence 
for dynamic, experience-induced alterations in DNA methylation emerges from studies of contextual fear conditioning, a hippocampal-dependent learning paradigm whereby an animal associates a novel context with an aversive stimulus and is accompanied by broad increases in H3K9ac (Vecsey et al, 2007; Lubin et al, 2008; Miller and Sweatt, 2007; Sweatt, 2009), dependent upon activation of the ERK/MAPK signaling pathway and the CREB-binding protein. Dynamic changes in DNA methylation at specific genomic sites appear crucial for learning and memory (Day and Sweatt, 2011). Adult neurons show high levels of expression for the de novo methylation enzymes, DNMT3a and $3 \mathrm{~b}$. Moreover, there is considerable regional specificity in DNMT expression in the adult rat brain, suggesting a specialized function in adulthood (Brown et al, 2008). Increases in DNMT3a and $3 \mathrm{~b}$ expression accompany contextual fear conditioning, and drugs that block DNMT activity impair conditioning (Miller and Sweatt, 2007). DNMT-deficient mice show impaired contextual fear conditioning (Feng et al, 2010). More recent studies identify specific genomic targets. Fear conditioning results in the methylation and transcriptional silencing of the gene for protein phosphatase 1 , which associates with the suppression of learning (Sweatt, 2009). The same training results in the demethylation of a proximal promoter and transcriptional activation of the synaptic plasticity gene reelin.

These findings strongly imply that both DNA methylation and demethylation might be involved in the activitydependent signaling pathways that underlie long-term memory consolidation. Brain-derived neurotrophic factor is an important example (Martinowich et al, 2003). More recent studies Guo et al, (2011) used next-generation sequencing for a genome-wide analysis of $\mathrm{CpG}$ methylation of adult mouse dentate granule neurons in vivo before and after synchronous neuronal activation (electroconvulsive stimulation; Guo et al (2011)). About $1.4 \%$ of the CpGs examined showed rapid active demethylation or de novo methylation, with some modifications remaining stable for at least $24 \mathrm{~h}$. These activity-modified CpGs showed a broad genomic distribution with significant enrichment in lowCpG-density regions, and were associated with brainspecific genes related to neuronal plasticity. The low-CpGdensity regions are of interest as the tightest correlations between DNA methylation and transcription are observed in such regions (Weber et al, 2007).

Taken together these findings suggest considerable capacity for active remodeling of DNA methylation. These findings are consistent with the prominent expression of DNMTs in neurons over adulthood and the degree to which DNMT expression as well as that of candidate demethylating agents is dynamically regulated by activity-dependent extracellular signals (Grayson et al, 2009; Ma et al, 2009). As treatments that target histone acetylation, such as HDAC inhibitors, can influence DNA methylation (Szyf, 2009), it might be possible to affect changes in DNA methylation through more accessible targets such as the histone posttranslational modifications that directly regulate chromatin structure. However, the pathways that lead to the remodeling of DNA methylation, especially those implicated in DNA demethylation, have yet to be fully identified. A related question concerns the variability across in the genome in the capacity for epigenetic remodeling. We have yet to identify the factors that determine the sensitivity of genomic regions to active remodeling. One interesting possibility is that such variation, either across genomic regions or within the same genomic regions and across individuals, may be related to underlying sequence variation (Zhang et al, 2010). For example, methylation of a $B D N F$ exon is associated with the well-known rs6265 (val66met) single-nucleotide polymorphism in the BDNF gene (Mill et al, 2006). Interestingly, the same polymorphism interacts with early-life adversity to influence hippocampal volume and the risk for depression (Gatt et al, 2009).

We have seen no underlying sequence variants in the various exon 1 regions of the NR3C1 gene in the course of our sodium bisulfite mapping with either rat or human samples. However, such findings do not preclude variants at other sites, including those regions affecting the relevant intracellular signaling pathways. Studies linking genomic sequence variants to differential sensitivity to intervention (eg, Bakermans-Kranenburg et al, 2008) beg the question of whether such individual differences suggest a variation in the capacity for epigenetic remodeling.

\section{SUMMARY}

The results of the studies suggest that epigenetic mechanisms serve to mediate the association between early childhood and gene expression, and thus to explain, in part at least, individual differences in vulnerability/resistance for specific forms of psychopathology. We focused on the regulation of hippocampal GR expression as a model and provide evidence for parental effects on hippocampal GR expression that associate with differences in the methylation of exon 1 promoters. There is now evidence for comparable environmental effects at multiple regions of the genome (eg, Roth et al, 2009; Murgatroy et al, 2009).

Indeed the value of the energetically costly brain is to guide the function of the organism in accordance with its life history. The ability to mastermind such adaptation to circumstance relies upon the capacity of neurons and glia to dynamically adapt genomic structure and function (Meaney and Ferguson-Smith, 2010). The implicit hypothesis is that environmental signals alter chromatin modifications that then serve as the mechanism for the transcriptional 'plasticity' that mediates sustained variation in neural function. Ironically, the dynamic nature and environmental sensitivity of DNA methylation in fully differentiated cells is somewhat at odds with the very stability that suggests DNA methylation as a mechanism for parental effects on gene expression. How do we square the dynamic nature of DNA methylation with the phenotypic 'programing' associated with parental effects? We actually know rather little about the variation in methylation marks at specific loci over time 
within the same individual. Perhaps a similar caveat applies to parental effects, studies of which often take the form of characterizing a parental signal at one stage of development, and then examining epigenetic states and phenotype at a later phase of life. The process of cell specialization that defines neural development depends upon the silencing on non-neural genes. This process can be activated in vitro in stem cells and the resulting repression initially involves Histone 3 lysine 27 tri-methylation, a polycomb-mediated, repressive histone modification (Mohn et al, 2008; and also see Cedar and Bergman, 2009). Repression then comes to reflect increased DNA methylation as neural differentiation proceeds, which is then thought to stabilize gene silencing. However, multiple regions of the genome in neural tissues are enriched for bidirectional histone modifications (ie, those associated with transcriptional activation, such as Histone 3 lysine 4 tri-methylation, as well as repression, notably H3K27me3), a characteristic of pluripotent cells (Bernstein et al, 2005). Such 'bi-valency' might define the potential for plasticity (Meaney and Ferguson-Smith, 2010). Repressive epigenetic contexts occur as a function of different epigenetic repertoires, which may vary in reversibility and confer variable environmental sensitivity (McEwen and Ferguson-Smith, 2010).

The challenge is that of defining causal pathways between environmental event, epigenetic mark, and genome function. In the context of the research on the parental regulation of hippocampal GR expression, future studies will need to focus on the mechanisms by which differential methylation of the exon 1 sequences affect transcription. A particularly interesting issue will be that of defining the processes that determine the relative stability and reversibility of parental effects.

\section{ACKNOWLEDGEMENTS}

The studies reviewed here from the authors labs as well those providing new data were supported by grants from the Canadian Institutes for Health Research to MJM and GT.

\section{DISCLOSURE}

The authors declare no conflict of interest.

\section{REFERENCES}

Adams AD, Choate DM, Thompson MA (1995). NF1-L is the DNA-binding component of the protein complex at the peripherin negative regulatory element. J Biol Chem 270: 6975-6983.

Alt SR, Turner JD, Klok MD, Lakke EAJF, Meijer OC, deRijk RH et al (2010). Differential expression of glucocorticoid receptor transcripts in major depressive disorder is not epigenetically programmed. Psychoneuroendocrinology 35: 544-556.

Ammerman RT, Cassisi JE, Hersen M, van Hasselt VB (1986). Consequences of physical abuse and neglect in children. Clin Psychol Rev 6: 291-310.

Bakermans-Kranenburg MJ, van IJzendoorn MH, Pijlman FT, Mesman J, Juffer F (2008). Experimental evidence for differential susceptibility: dopamine D4 receptor polymorphism (DRD4 VNTR) moderates intervention effects on toddlers' externalizing behavior in a randomized controlled trial. Dev Psychol 44: 293-300.
Barden N (2004). Implication of the hypothalamic-pituitary-adrenal axis in the physiopathology of depression. J Psychiatry Neurosci 29: 185-193.

Belsky J (1997). Theory testing, effect-size evaluation, and differential susceptibility to rearing influence: the case of mothering and attachment. Child Devel 64: 598-600.

Berger SL (2007). The complex language of chromatin regulation during transcription. Nature 447: 407-412.

Bernstein BE, Kamal M, Lindblad-Toh K, Bekiranov S, Bailey DK, Huebert DJ et al (2005). Genomic maps and comparative analysis of histone modifications in human and mouse. Cell 120: 169-181.

Bifulco A, Brown GW, Adler Z (1991). Early sexual abuse and clinical depression in adult life. Br J Psychiat 159: 115-122.

Bird A (2001). Molecular biology. Methylation talk between histones and DNA. Science 294: 2113-2115.

Bird AP, Wolffe AP (1999). Methylation-induced repression-belts, braces, and chromatin. Cell 99: 451-454.

Boyle MP, Brewer JA, Funatsu M, Wozniak DF, Tsien JZ, Izumi Y et al (2005). Acquired deficit of forebrain glucocorticoid receptor produces depression-like changes in adrenal axis regulation and behavior. Proc Natl Acad Sci USA 102: 473-478

Brandeis M, Frank D, Keshet I, Siegfried Z, Mendelsohn M, Nemes A et al (1994). Sp1 elements protect a CpG island from de novo methylation. Nature 371: 435-438.

Brodin G, Ahgren A, ten Dijke P, Heldin CH, Heuchel R (2000). Efficient TGF-beta induction of the Smad7 gene requires cooperation between AP-1, Sp1, and Smad proteins on the mouse Smad7 promoter. J Biol Chem 275: 29023-29030.

Brown GR, Anderson B (1991). Psychiatric morbidity in adult inpatients with childhood histories of sexual and physical abuse. Am J Psychiat 148: 55-61.

Brown SE, Weaver IC, Meaney MJ, Szyf M (2008). Regional-specific global cytosine methylation and DNA methyltransferase expression in the adult rat hippocampus. Neurosci Lett 440: 49-53.

Caldji C, Diorio J, Meaney MJ (2003). Variations in maternal care alter GABA receptor subunit expression in brain regions associated with fear. Neuropsychopharmacology 28: 150-159.

Caldji C, Francis DD, Sharma S, Plotsky PM, Meaney MJ (2000). The effects of early rearing environment on the development of GABAA and central benzodiazepine receptor levels and novelty-induced fearfulness in the rat. Neuropsychopharmacology 22: 219-229.

Caldji C, Tannenbaum B, Sharma S, Francis D, Plotsky PM, Meaney MJ (1998). Maternal care during infancy regulates the development of neural systems mediating the expression of behavioral fearfulness in adulthood in the rat. Proc Nat Acad Sci 95: 5335-5340.

Cameron NM, Champagne FA, Parent C, Fish EW, Ozaki-Kuroda K, Meaney MJ (2005). The programming of individual differences in defensive responses and reproductive strategies in the rat through variations in maternal care. Neurosci Biobehav Rev 29: 843-865.

Canetti L, Bachar E, Galili-Weisstub E, De-Nour AK, Shalev AY (1997). Parental bonding and mental health in adolesence. Adolescence 32: 381-394.

Cedar H, Bergman Y (2009). Linking DNA methylation and histone modification: patterns and paradigms. Nature Rev Genet 10: 295-304.

Champagne FA, Francis DD, Mar A, Meaney MJ (2003). Variations in maternal care in the rat as a mediating influence for the effects of environment on development. Physiol Behav 79: 359-371.

Cicchetti D, Rogosch FA, Gunnar MR, Toth SL (2010). The differential impacts of early abuse on internalizing problems and diurnal cortisol activity in school-aged children. Child Devel 25: 252-269.

Ciccone DN, Su H, Hevi S, Gay F, Lei H, Bajko J et al (2009). KDM1B is a histone H3K4 demethylase required to establish maternal genomic imprints. Nature 461: 415-418.

Conger RD, Donnellan MB (2007). An interactionist perspective on the socioeconomic context of human development. Annu Rev Psychol 58: 157-199.

Crosby SD, Puetz JJ, Simburger KS, Fahrner TJ, Milbrandt J (1991). The early response gene NGFI-C encodes a zinc finger transcriptional activator and is a member of the GCGGGGGCG (GSG) element-binding protein family. Mol Cell Biol 11: 3835-3841.

Day JJ, Sweat JD (2011). Epigenetic mechanisms in cognition. Neuron 70: 813-829.

DeBattista C, Belanoff J, Glass S, Khan A, Horne RL et al (2006). Mifepristone versus placebo in the treatment of psychosis in patients with psychotic major depression. Biol Psychiatry 60: 1343-1349.

DeBellis MD, Chrousos GP, Dorn LD, Burke L, Helmers K, Kling MA et al (1994). Hypothalamic-pituitary-adrenal dysregulation in sexually abused girls. J Clin Endocrinol Metab 78: 249-255.

de Kloet ER, Joels M, Holsboer F (2005). Stress and the brain: from adaptation to disease. Nat Rev Neurosci 6: 463-475. 
Dumais A, Lesage AD, Alda M, Rouleau G, Dumont M, Chawky N et al (2005). Risk factors for suicide completion in major depression: a case-control study of impulsive and aggressive behaviors in men. Am J Psychiatry 162: 2116-2124.

Essex MJ, Klein MH, Cho E, Kalin NH (2002). Maternal stress beginning in infancy may sensitize children to later stress exposure: effects on cortisol and behavior. Biol Psychiatry 52: 776-784

Felitti VJ, Anda RF, Nordenberg D, Williamson DF, Spitz AM, Edwards V et al (1998). Relationship of childhood abuse and household dysfunction to many of the leading causes of death in adults. Am J Prevent Med 14: 245-258.

Feng J, Zhou Y, Campbell SL, Le T, Li E, Sweatt JD et al (2010). Dnmt1 and Dnmt3a maintain DNA methylation and regulate synaptic function in adult forebrain neurons. Nature Neurosci 13: 423-430.

Fish EW, Shahrokh D, Bagot R, Caldji C, Bredy T, Szyf M et al (2004). Epigenetic programming of stress responses through variations in maternal care. Ann N Y Acad Sci 1036: 167-180.

Flinn MV, England BG (1995). Childhood stress and family environment. Curr Anthropol 5: 1569-1579.

Fisher PA, Gunnar MR, Chamberlain P, Reid JB (2000). Preventive intervention for maltreated preschool children: impact on children's behavior, neuroendocrine activity, and foster parent functioning. J Am Acad Child Adolesc Psychiatry 39: 1356-1364.

Francis D, Diorio J, Liu D, Meaney MJ (1999). Nongenomic transmission across generations of maternal behavior and stress responses in the rat. Science 286: 1155-1158.

Francis DD, Caldji C, Champagne F, Plotsky PM, Meaney MJ (1999a). The role of corticotropin-releasing factor-norepinephrine systems in mediating the effects of early experience on the development of behavioral and endocrine responses to stress. Biol Psychiatry 46: 1153-1166.

Gatt J, Nemeroff C, Dobson-Stone C, Paul R, Bryant R, Schofield P et al (2009). Interactions between BDNF Val66Met polymorphism and early life stress predict brain and arousal pathways to syndromal depression and anxiety. Psychiat 14: 681-695.

Gross C, Hen R (2004). The developmental origins of anxiety. Nat Rev Neurosci 5 : 545-552.

Gross C, Zhuang X, Stark K, Ramboz S, Oosting R, Kirby L et al (2002). Serotonin1A receptor acts during development to establish normal anxiety-like behaviour in the adult. Nature 416: 396-400.

Gottman JM (1998). Psychology and the study of marital processes. Ann Rev Psychol 49: 169-197.

Grayson DR, Chen Y, Dong E, Kundakovic M, Guidotti A (2009). From transmethylation to cytosine methylation: evolution of the methylation hypothesis of schizophrenia. Epigenetics 4: 144-149.

Grayson DR, Jia X, Chen Y, Sharma RP, Mitchell CP, Guidotti A et al (2005). Reelin promoter hypermethylation in schizophrenia. Proc Natl Acad Sci USA 102: 9341-9346.

Grunstein M (1997). Histone acetylation in chromatin structure and transcription. Nature 389: 349-352.

Guo JU, Ma DK, Mo H, Ball MP, Jang MH, Bonaguidi MA et al (2011). Neuronal activity modifies the DNA methylation landscape in the adult brain. Nature Neurosci 14: 1345-1351.

Hackman D, Farah MJ, Meaney MJ (2010). Socioeconomic status and the brain: mechanistic insights from human and animal research. Nature Rev Neurosci 11: $651-659$.

Hake SB, Allis CD (2006). Histone H3 variants and their potential role in indexing mammalian genomes: the 'H3 barcode hypothesis'. Proc Natl Acad Sci USA 103: 6428-6435.

Heim C, Newport DJ, Heit S, Graham YP, Wilcox M, Bonsall R et al (2000). Pituitaryadrenal and autonomic responses to stress in women after sexual and physical abuse in childhood. JAMA 284: 592-597.

Hernandez DG, Nalls MA, Gibbs JR, Arepalli S, van der Brug M, Sean Chong S et al (2011). Distinct DNA methylation changes highly correlated with chronological age in the human brain. Human Mol Genet 20: 1164-1172.

Holmes SJ, Robins LN (1987). The influence of childhood disciplinary experience on the development of alcoholism and depression. J Child Psychol Psychiatry 28: 399-415.

Holmes S, Robins LN (1988). The role of parental disciplinary practices in the development of depression and alcoholism. Psychiatry 51: 24-36.

Hill J, Davis R, Byatt M, Burnside E, Rollinson L, Fear S (2000). Childhood sexual abuse and affective symptoms in women: a general population study. Psychol Med 30: 1283-1291.

Hill J, Pickles A, Burnside E, Byatt M, Rollinson L, Davis R et al (2001). Child sexual abuse, poor parental care and adult depression: evidence for difference mechanisms. Br J Psychiatry 179: 104-109.

Holsboer F (2000). The corticosteroid receptor hypothesis of depression. Neuropsychopharmacology 23: 477-501.
Hurst HC, Jones NC (1987). Identification of factors that interact with the E1Ainducible adenovirus E3 promoter. Genes Dev 1: 1132-1146.

Inoue T, Tamura T, Furuichi T, Mikoshiba K (1990). Isolation of complementary DNAs encoding a cerebellum-enriched nuclear factor I family that activates transcription from the mouse myelin basic protein promoter. $J$ Biol Chem 265: 19065-19070.

Jenuwein T, Allis CD (2001). Translating the histone code. Science 293: 1074-1080. Kardassis D, Papakosta P, Pardali K, Moustakas A (1999). C-Jun transactivates the promoter of the human p21(WAF1/Cip1) gene by acting as a superactivator of the ubiquitous transcription factor Sp1. J Biol Chem 274: 29572-29581.

Kendler KS, Gardner CO, Prescott CA (2002). Towards a comprehensive developmental model for major depression in women. Am J Psychiatry 159: 1133-1145.

Klaassens ER, van Noorden MS, Giltay MS, van Pelt J, van Veen T, Zitman FG (2009). Effects of childhood trauma on HPA-axis reactivity in women free of lifetime psychopathology. Prog Neuro-Psychopharmacol Biol Psychiatry 33: 889-894.

Klein Velderman M, Bakermans-Kranenburg MJ, Juffer F, Van IJzendoorn MH (2006). Effects of attachment-based interventions on maternal sensitivity and infant attachment: differential susceptibility of highly reactive infants. J Fam Psychol 20: 266-274.

Klose RJ, Bird AP (2006). Genomic DNA methylation: the mark and its mediators. Trends Biochem Sci 31: 89-97.

Kouzarides T (2007). Chromatin modifications and their function. Cell 128: 693-705. Kriaucionis S, Heintz N (2009). The nuclear DNA base5-hydroxymethylcytosine is present in Purkinje neurons and the brain. Science 324: 929-930.

Kundakovic M, Chen Y, Costa E, Grayson DR (2007). DNA methyltransferase inhibitors coordinately induce expression of the human reelin and glutamic acid decarboxylase 67 genes. Mol Pharmacol 71: 644-653.

Kurata A, Morinobu S, Fuchikami M, Yamamoto S, Yamawaki S (2009). Maternal postpartum learned helplessness $(\mathrm{LH})$ affects maternal care by dams and responses to the LH test in adolescent offspring. Horm Behav 56: 112-120.

Laniel MA, Poirier GG, Guerin SL (2001). Nuclear factor 1 interferes with Sp1 binding through a composite element on the rat poly(ADP-ribose) polymerase promoter to modulate its activity in vitro. J Biol Chem 276: 20766-20773.

Laplante P, Diorio J, Meaney MJ (2002). Serotonin regulates hippocampal glucocorticoid receptor expression via a 5-HT7 receptor. Brain Res Dev Brain Res 139: 199-203.

Lee R, Geracioti TD Jr., Kasckow JW, Coccaro EF (2005). Childhood trauma and personality disorder: positive correlation with adult CSF corticotropin-releasing factor concentrations. Am J Psychiatry 162: 995-997.

Leucken LJ (1998). Childhood attachment and loss experiences affect adult cardiovascular and cortisol function. Psychosom Med 60: 765-770.

Leucken LJ (2000). Parental caring and loss during childhood and adult cortisol responses to stress. Psychol Health 15: 841-851.

Li E (2002). Chromatin modification and epigenetic reprogramming in mammalian development. Nat Rev Genet 3: 662-673.

Linver MR, Brooks-Gunn J, Kohen DE (2002). Family processes as pathways from income to young children's development. Dev Psychol 38: 719-734.

Liu D, Diorio J, Tannenbaum B, Caldji C, Francis D, Freedman A et al (1997). Maternal care, hippocampal glucocorticoid receptors, and hypothalamicpituitary-adrenal responses to stress. Science 277: 1659-1662.

Lubin FD, Roth TL, Sweatt JD (2008). Epigenetic regulation of bdnf gene transcription in the consolidation of fear memory. J Neurosci 28: 10576-10586.

Luecken LJ, Lemery KS (2004). Early caregiving and physiological stress responses. Clin Psych Rev 24: 171-191.

Lupien SJ, McEwen BS, Gunnar MR, Heim C (2009). Effects of stress throughout the lifespan on the brain, behaviour and cognition. Nature Rev Neurosci 10: 434-445

Ma DK, Jang MH, Guo JU, Kitabatake Y, Chang ML, Pow-Anpongkul N et al (2009). Neuron activity-induced Gadd45b promotes epigenetic DNA demethylation and adult neurogenesis. Science 323: 1074-1077.

Macleod D, Charlton J, Mullins J, Bird AP (1994). Spl sites in the mouse aprt gene promoter are required to prevent methylation of the $\mathrm{CpG}$ island. Genes Devel 8: 2282-2292.

Maestripieri D, Mateo J (2009). Maternal effects in mammals. In: Maestripieri D, Mateo JM (eds). The University of Chicago Press: Chicago.

Martinowich K, Hattori D, Wu H, Fouse S, He F, Hu Y et al (2003). DNA methylationrelated chromatin remodeling in activity-dependent BDNF gene regulation. Science 302: 890-893.

McCauley J, Kern DE, Kolodner K, Dill L, Schroeder AF, DeChant HK et al (1997). Clinical characteristics of women with a history of childhood abuse: unhealed wounds. JAMA 277: 1362-1368.

McCormick JA, Lyons V, Jacobson MD, Noble J, Diorio J, Nyirenda M et al (2000). $5^{\prime}$-Heterogeneity of glucocorticoid receptor messenger RNA is tissue specific: 
differential regulation of variant transcripts by early-life events. Mol Endocrinol 14 506-517.

McEwen KR, Ferguson-Smith AC (2010). Distinguishing epigenetic marks of developmental and imprinting regulation. Epigenet Chromat 3: 2.

McGowan PO, Sasaki A, D’Alessio AC, Dymov S, Labonte B, Szyf M et al (2009). Epigenetic regulation of the glucocorticoid receptor in human brain associates with childhood abuse. Nat Neurosci 12: 342-348.

McGowan PO, Suderman M, Sasaki A, Huang TC, Hallett M, Meaney MJ et al (2011). Broad epigenetic signature of maternal care in the brain of adult rats. PLoS One 6: e14739.

McLoyd VC (1998). Socioeconomic disadvantage and child development. Am Psychol 53: 185-204.

Meaney MJ (2001). Maternal care, gene expression, and the transmission of individual differences in stress reactivity across generations. Annu Rev Neurosci 24: 1161-1192.

Meaney MJ, Aitken DH, Sapolsky RM (1987). Thyroid hormones influence the development of hippocampal glucocorticoid receptors in the rat: a mechanism for the effects of postnatal handling on the development of the adrenocortical stress response. Neuroendocrinology 45: 278-283.

Meaney MJ, Diorio J, Francis D, Weaver S, Yau J, Chapman K et al (2000). Postnatal handling increases the expression of CAMP-inducible transcription factors in the rat hippocampus: the effects of thyroid hormones and serotonin. J Neurosci 20: 3926-3935.

Meaney MJ, Ferguson-Smith A (2010). Epigenomic regulation of the neural transcriptome: the meaning of the marks. Nature Neurosci 13: 1313-1318.

Menard J, Champagne D, Meaney MJ (2004). Variations of maternal care differentially influence 'fear' reactivity and regional patterns of cFos immunoreactivity in response to the shock-probe burying test. Neuroscience 129: 297-308.

Mill J, Dempster E, Caspi A, Williams B, Moffitt T, Craig I (2006). Evidence for monozygotic twin (MZ) discordance in methylation level at two CpG sites in the promoter region of the catechol-O-methylransferase (COMT) gene. Am J Med Genet B Neuropsychiatr Genet 141: 421-425.

Miller CA, Sweatt JD (2007). Covalent modification of DNA regulates memory formation. Neuron 53: 857-869.

Millar CB, Grunstein M (2006). Genome-wide patterns of histone modifications in yeast. Nat Rev Mol Cell Biol 7: 657-666.

Miranda TB, Jones PA (2007). DNA methylation: the nuts and bolts of repression. J Cell Physiol 213: 384-390.

Mitchell JB, Betito K, Rowe W, Boksa P, Meaney MJ (1992). Serotonergic regulation of type II corticosteroid receptor binding in cultured hippocampal cells: the role of serotonin-induced increases in cAMP levels. Neuroscience 48: 631-639.

Mitchell JB, Iny LJ, Meaney MJ (1990). The role of serotonin in the development and environmental regulation of type $\|$ corticosteroid receptor binding in rat hippocampus. Brain Res Dev Brain Res 55: 231-235.

Mohn F, Weber M, Rebhan M, Roloff TC, Richter J, Stadler MB et al (2008). Lineage-specific polycomb targets and de novo DNA methylation define restriction and potential of neuronal progenitors. Mol Cell 30: 755-766.

Murgatroyd C, Patchev AV, Wu Y, Micale V, Bockmuhl Y, Fischer D et al (2009). Dynamic DNA methylation programs persistent adverse effects of early-life stress. Nat Neurosci 12: 1559-1566.

Nan X, Ng HH, Johnson CA, Laherty CD, Turner BM, Eisenman RN et al (1998). Transcriptional repression by the methyl-CpG-binding protein MeCP2 involves a histone deacetylase complex. Nature 393: 386-389.

Neigh GN, Nemeroff CB (2006). Reduced glucocorticoid receptors: consequence or cause of depression? Trends Endocrinol Metab 17: 124-125.

Nemeroff CB (1996). The corticotropin-releasing factor (CRF) hypothesis of depression: new findings and new directions. Mol Psychiatry 1: 336-342.

Nobukuni Y, Smith CL, Hager GL, Detera-Wadleigh SD (1995). Characterization of the human glucocorticoid receptor promoter. Biochemistry 34: 8207-8214

Noh JS, Sharma RP, Veldic M, Salvacion AA, Jia X, Chen Y et al (2005). DNA methyltransferase 1 regulates reelin mRNA expression in mouse primary cortical cultures. Proc Natl Acad Sci USA 102: 1749-1754.

Oberlander T, Weinberg J, Papsdorf M, Grunau R, Misri S, Devlin A (2008). Prenatal exposure to maternal depression, neonatal methylation of human glucocorticoid receptor gene (NR3C1) and infant cortisol stress responses. Epigenetics 3: 97-106.

Olds D, Henderson CR, Cole R, Eckenrode J, Kitzman H, Luckey D et al (1998). Long-term effects of nurse home visitation on children's criminal and antisocial behavior: 15-year follow-up of a randomized controlled trial. JAMA 280: 1238-1244

Ooi SK, Qiu C, Bernstein E, Li K, Jia D, Yang Z et al (2007). DNMT3L connects unmethylated lysine 4 of histone $\mathrm{H} 3$ to de novo methylation of DNA. Nature 448 : 714-717.
Parker G (1981). Parental representations of patients with anxiety neurosis. Acta Psychiatria Scand 63: 33-36.

Pascale RM, Simile MM, Satta G, Seddaiu MA, Daino L, Pinna G et al (1991). Comparative effects of L-methionine, S-adenosyl-L-methionine and 5' methylthioadenosine on the growth of preneoplastic lesions and DNA methylation in rat liver during the early stages of hepatocarcinogenesis. Anticancer Res 11: $1617-1624$

Pokholok DK, Harbison CT, Levine S, Cole M, Hannett NM, Lee TI et al (2005). Genome-wide map of nucleosome acetylation and methylation in yeast. Cell 122: 517-527.

Pruessner JL, Champagne FA, Meaney MJ, Dagher A (2004). Parental care and neuroendocrine and dopamine responses to stress in humans: a PET imaging study. J Neurosci 24: 2825-2831.

Radtke KM, Ruf M, Gunter HM, Dohrmann K, Schauer M, Meyer A et al (2011). Transgenerational impact of intimate partner violence on methylation in the promoter of the glucocorticoid receptor. Transl Psychiat 1: e21.

Rafty LA, Santiago FS, Khachigian LM (2002). NF1/X represses PDGF A-chain transcription by interacting with Sp1 and antagonizing Sp1 occupancy of the promoter. EMBO J 21: 334-343.

Reichardt HM, Tronche F, Bauer A, Schutz G (2000). Molecular genetic analysis of glucocorticoid signaling using the Cre/loxP system. Biol Chem 381: 961-964.

Reid WJ, Crisafulli A (1990). Marital discord and child behavior problems: a metaanalysis. J Abnorm Child Psychol 18: 105-117.

Roth T, Lubin F, Funk A, Sweatt J (2009). Lasting epigenetic influence of early-life adversity on the BDNF gene. Biol Psychiatry 65: 760-769.

Roy RJ, Guerin SL (1994). The 30-kDa rat liver transcription factor nuclear factor 1 binds the rat growth-hormone proximal silencer. Eur J Biochem/FEBS 219: 799-806

Repetti RL, Taylor SE, Seeman TE (2002). Risky families: family social environments and the mental and physical health of offspring. Psychol Bull 128: 330-366.

Ridder S, Chourbaji S, Hellweg R, Urani A, Zacher C, Schmid W et al (2005). Mice with genetically altered glucocorticoid receptor expression show altered sensitivity for stress-induced depressive reactions. J Neurosci 25: 6243-6250.

Russak LG, Schwartz GE (1997). Feelings of parental care predict health status in midlife: a 35 year follow-up of the Harvard Mastery of Stress Study. J Behav Med 20: $1-13$

Ruthenburg AJ, Allis CD, Wysocka J (2007a). Methylation of lysine 4 on histone H3: intricacy of writing and reading a single epigenetic mark. Mol Cell 25: 15-30.

Rutter M (1979). Protective factors in children's responses to stress and disadvantage. Prim Prev Psychopathol 3: 49-74.

Schatzberg AF, Rothschild AJ, Langlais PJ, Bird ED, Cole JO (1985). A corticosteroid/dopamine hypothesis for psychotic depression and related states. I Psychiatr Res 19: 57-64.

Seckl JR, Meaney MJ (1994). Early life events and later development of ischaemic heart disease. Lancet 342: 1236.

Shahbazian MD, Grunstein M (2007). Functions of site-specific histone acetylation and deacetylation. Annu Rev Biochem 76: 75-100.

Shonkoff JP, Boyce WT, McEwen BS (2009). Neuroscience, molecular biology, and the childhood roots of health disparities: building a new framework for health promotion and disease prevention. J Am Med Assoc 301: 2252-2259.

Smith J, Prior M (1995). Temperament and stress resilience in school-age children: a withinfamilies study. J Am Acad Child Adolesc Psychiatry 34: 168-179.

Sroufe LA (1997). Emotional Development. Cambridge University Press: Cambridge UK.

Sweatt JD (2009). Experience-dependent epigenetic modifications in the central nervous system. Biol Psychiatry 65: 191-197.

Szyf M (2009). Epigenetics, DNA methylation, and chromatin modifying drugs. Annu Rev Pharmacol Toxicol 49: 243-263.

Szyf M, Pakneshan P, Rabbani SA (2004). DNA demethylation and cancer: therapeutic implications. Cancer Lett 211: 133-143.

Tapias A, Ciudad CJ, Noe V (2008). Transcriptional regulation of the 5'-flanking region of the human transcription factor Sp3 gene by NF-1, c-Myb, B-Myb, AP-1 and E2F. Biochim Biophys Acta 1779: 318-329.

Taverna SD, Li H, Ruthenburg AJ, Allis CD, Patel DJ (2007). How chromatin-binding modules interpret histone modifications: lessons from professional pocket pickers. Nat Struct Mol Biol 14: 1025-1040.

Taylor SE, Eisenberger NI, Saxbe D, Lehman BJ, Lieberman MD (2006). Neural responses to emotional stimuli are associated with childhood family stress. Biol Psychiatry 60: 296-301.

Taylor SE, Lerner JS, Sage RM, Lehman BJ, Seeman TE (2004). Early environment, emotions, responses to stress, and health. Special issue on personality and health. J Pers 72: 1365-1393

Teicher MH, Andersen SL, Polcari A, Anderson CM, Navalta CP (2002). Developmental neurobiology of childhood stress and trauma. Psychiatr Clin North Am 25: 397-426, vii-viil. 
Thompson JP, Skene PJ, Selfridge J, Clouaire T, Guy J, Webb S et al (2010). CpG islands influence chromatin structure via the CpG-binding protein Cfp1. Nature 464: 1082-1086.

Tremolizzo L, Doueiri MS, Dong E, Grayson DR, Davis J, Pinna G et al (2005). Valproate corrects the schizophrenia-like epigenetic behavioral modifications induced by methionine in mice. Biol Psychiatry 57: 500-509.

Trickett PK, McBride-Chang C (1995). The developmental impact of different forms of child abuse and neglect. Dev Rev 15: 311-337.

Toki S, Morinobu S, Imanaka A, Yamamoto S, Yamawaki S, Honma K (2007). Importance of early lighting conditions in maternal care by dam as well as anxiety and memory later in life of offspring. Eur J Neurosci 25: 815-829.

Turner BM (2001). Chromatin Structure and the Regulation of Gene Expression. Blackwell Science Ltd.: Oxford.

Turner JD, Alt SR, Cao L, Vernocchi S, Trifonova S, Battello N et al (2010). Transcriptional control of the glucocorticoid receptor: $\mathrm{CpG}$ islands, epigenetics and more. Biochem Pharmacol 80: 1860-1868.

Turner JD, Muller CP (2005). Structure of the glucocorticoid receptor (NR3C1) gene $5^{\prime}$ untranslated region: identification, and tissue distribution of multiple new human exon 1. J Mol Endocrinol 35: 283-292.

Tyrka AR, Prince LH, Marsit C, Walters OC, Carpenter LL (2012). Childhood adversity and epigenetic modulation of the leukocyte glucocorticoid receptor: preliminary findings in healthy adults. PloS One 7: e30148.

van Hasselt FN, Cornelisse S, Zhang TY, Meaney MJ, Velzing EH, Krugers HJ et al (2012). Adult hippocampal glucocorticoid receptor expression and dentate synaptic plasticity correlate with maternal care received by individuals early in life. Hippocampus 22: 255-266.

van Rossum EF, Binder EB, Majer M, Koper JW, Isin M, Modell S et al (2006). Polymorphisms of the glucocorticoid receptor gene and major depression. Biol. Psychiatry 59: 681-688.

van West D, Del-Favero J, Aulchenko Y, Oswald P, Souery D, Forsgren T et al (2004). A major SNP haplotype of the arginine vasopressin1B receptor protects against recurrent major depression. Molec Psychiatry 9: 287-292.

Van Zeijl J, Mesman J, Van IJzendoorn MH (2006). Attachment based intervention for enhancing sensitive discipline in mothers of 1 - to 3 -year-old children at risk for externalizing behavior problems: a randomized controlled trial. J Consult Clin Psychol 74: 994-1005.

Vecsey CG, Hawk JD, Lattal KM, Stein JM, Fabian SA, Attner MA et al (2007). Histone deacetylase inhibitors enhance memory and synaptic plasticity via CREB: CBP-dependent transcriptional activation. J Neurosci 27: 6128-6140.

Weaver ICG, Cervoni N, D'Alessio AC, Champagne FA, Seckl JR, Szyf M et al (2004). Epigenetic programming through maternal behavior. Nat Neurosci 7: $847-854$.
Weaver ICG, Champagne FA, Brown SE, Dymov S, Sharma S, Meaney MJ et al (2005). Reversal of maternal programming of stress responses in adult offspring through methyl supplementation: altering epigenetic marking later in life. J Neurosci 25: 11045-11054

Weaver IC, DiAlessio AC, Brown SE, Hellstrom IC, Dymov S, Diorio J et al (2007). The transcription factor NGFI-A mediates epigenetic programming: altering epigenetic marking through immediate early genes. J Neuroscience 27: 1756-1768.

Weaver IC, Meaney MJ, Szyf M (2006). Maternal care effects on the hippocampal transcriptome and anxiety-mediated behaviors in the offspring that are reversible in adulthood. Proc Natl Acad Sci USA 103: 3480-3485.

Weber M, Hellmann I, Stadler MB, Ramos L, Pääbo S, Rebhan M et al (2007). Distribution, silencing potential and evolutionary impact of promoter DNA methylation in the human genome. Nature Genet 39: 457-466.

Webster MJ, Knable MB, O'Grady J, Orthmann J, Weickert CS (2002). Regional specificity of brain glucocorticoid receptor mRNA alterations in subjects with schizophrenia and mood disorders. Mol Psychiatry 7: 985-994. , 924.

Wichers M, Geschwind N, Jacobs N, Kenis G, Peeters F, Derom C et al (2009). Transition from stress sensitivity to a depressive state: longitudinal twin study. $\mathrm{Br}$ J Psychiatry 195: 498-503.

Wichers M, Myin-Germeys I, Jacobs N, Peeters F, Kenis G, Derom C et al (2007). Genetic risk of depression and stress-induced negative affect in daily life. $\mathrm{Br} \mathrm{J}$ Psychiatry 191: 218-223.

Widom CS, DuMont K, Czaja SJ (2007). A prospective investigation of major depressive disorder and comorbidity in abused and neglected children grown up. Arch Gen Psychiatry 64: 49-56.

Zhang TY, Bagot R, Parent C, Nesbitt C, Bredy TW, Caldji C et al (2006). Maternal programming of defensive responses through sustained effects on gene expression. Biol Psychiatry 73: 72-89.

Zhang TY, Meaney MJ (2010). Epigenetics and the environmental regulation of the genome and its function. Annu Rev Psychol 61: 439-466. C431-433.

Zhang D, Cheng L, Badner JA, Chen C, Luo W, Craig DW et al (2010). Genetic control of individual differences in gene-specific methylation in human brain. Am J Hum, Genet 86: 411-419.

Zhang TY, Hellstrom IC, Bagot RC, Wen X, Diorio J, Meaney MJ (2010a). Maternal care and DNA methylation of the glutamic acid decarboxylase / promoter in rat hippocampus. J Neuroscience 30: 13130-13107.

Zouk H, Tousignant M, Seguin M, Lesage A, Turecki G (2006). Characterization of impulsivity in suicide completers: clinical, behavioral and psychosocial dimensions. J Affect Dis 92: 195-204. 